\title{
An All-Optical Grooming Switch for Interconnecting Access and Metro Ring Networks [Invited]
}

\author{
R. Bonk, P. Vorreau, D. Hillerkuss, W. Freude, G. Zarris, D. Simeonidou, F. Parmigiani, P. Petropoulos, \\ R. Weerasuriya, S. Ibrahim, A. D. Ellis, D. Klonidis, I. Tomkos, and J. Leuthold
}

\begin{abstract}
A regenerative all-optical grooming switch for interconnecting $130 \mathrm{Gbit} / \mathrm{s}$ on-off keying (OOK) metro/core ring and $43 \mathrm{Gbit} / \mathrm{s}-\mathrm{OOK}$ metro/access ring networks with switching functionality in time, space, and wavelength domains is demonstrated. Key functionalities of the switch are traffic aggregation with time-slot interchanging functionality, optical time division multiplexing (OTDM) to wavelength division multiplexing (WDM) demultiplexing, and multi-wavelength $2 R$ regeneration. Laboratory and field demonstrations show the excellent performance of the new concept with error-free signal transmission and $Q$-factors above $20 \mathrm{~dB}$.
\end{abstract}

Index Terms-All-optical networks; Nonlinear optics; Routers; switches; and multiplexers.

\section{INTRODUCTION}

$\mathbf{O}$ ptical communication networks have undergone a great evolution during the last few years due to the enormous growth of IP traffic. To cope with the bandwidth demand of the users, very high capacity long-haul links have been deployed worldwide [1]. Long-haul networks are optimized for optical transmission and switching of high capacity traffic volume, thanks to innovations especially in wavelength division multiplexing (WDM) technology [2]. Simultaneously, new access technologies are pushing the fiber to the end-user, supporting new large bandwidth applications such as video-on-demand and online gaming [3]. Access data rates have increased from $\mathrm{kbit} / \mathrm{s}$ to $\mathrm{Mbit} / \mathrm{s}$, and new emerging technologies promise even higher data rates up to Gbit/s per user. Metropolitan area networks (MANs) will need significant improvement in both capacity and functionality in order to cope with the foreseen bandwidth demand [4]. The technology leaps in the backbone

Manuscript received October 12, 2010; accepted December 9, 2010; published February 28, 2011 (Doc. ID 136273).

R. Bonk (e-mail: rene.bonk@kit.edu), P. Vorreau, D. Hillerkuss, W. Freude, and J. Leuthold (e-mail: juerg.leuthold@kit.edu) are with the Institute of Photonics and Quantum Electronics, Karlsruhe Institute of Technology (KIT), 76131 Karlsruhe, Germany.

G. Zarris and D. Simeonidou are with the School of Computer Science and Electronics Engineering, University of Essex, CO4 3SQ, United Kingdom.

F. Parmigiani and P. Petropoulos are with the Optoelectronics Research Centre, University of Southampton, United Kingdom.

R. Weerasuriya, S. Ibrahim, and A. D. Ellis are with the Photonic Systems Group, Department of Physics, University College Cork, Cork, Ireland.

D. Klonidis and I. Tomkos (e-mail: itom@ait.edu.gr) are with Athens Information Technology, Athens, Greece.

Digital Object Identifier 10.1364/JOCN.3.000206 and access parts of the network have so far not been matched with progress in the metro part. This is known as the metro gap [5]. The challenge for next generation metro networks is to flexibly aggregate, transmit, and switch the high volume continuous and burst traffic between the backbone and access networks in a highly cost efficient way [6] in order to handle the new dynamic services and applications.

Most metro networks today are of a traditional architecture and consist of synchronous digital hierarchy (SDH)/synchronous optical network (SONET) interconnected rings [7]. SDH/SONET formats were developed when voice was the dominant end-user application. Therefore this format is circuit-switching oriented and most efficient for multiplexing a large number of low rate circuits. The metro network structure comprises SDH/SONET rings that can be subdivided into metro/access rings and metro/core rings. Metro/access rings are also known as edge rings that collect and aggregate the data from the customer sites. Metro/core rings do further data aggregation and then feed them to the long-haul network.

Today, optical wavelength (circuit) routers are able to transparently switch (non-blocking) traffic within the same network. However, switching of data between networks (metro/core and metro/access rings) is performed using costly optical-electrical-optical (OEO) conversion [8,9]. These electrically switched digital cross-connects (DXCs) are able to perform time-slot interchange (TSI) and spatial switching. It should be noted that the use of DXCs at these points of the network aids bandwidth management by providing excellent traffic grooming capabilities. Signal regeneration is taking place at every DXC node.

However, the OEO conversion makes DXCs expensive and complex, with large footprints and power consumption [8,9]. Furthermore, this electronic technology has proved to be very restrictive, exhibiting cumbersome provisioning procedures. For example, a bandwidth upgrade for a ring means that all DXC interfaces have to be upgraded, which is a costly, time-consuming, and traffic disruptive procedure.

Future transparent optical switches need to offer the functionality already available in the electronic domain such as time and spatial switching as well as traffic grooming. Optical switches have already shown the potential to overcome the issues of the electrical-based DXCs and especially the bandwidth limitation. Optical processing is also considered to be highly energy efficient and may lead to switches requiring less overall footprint compared to their electronic counterparts. 

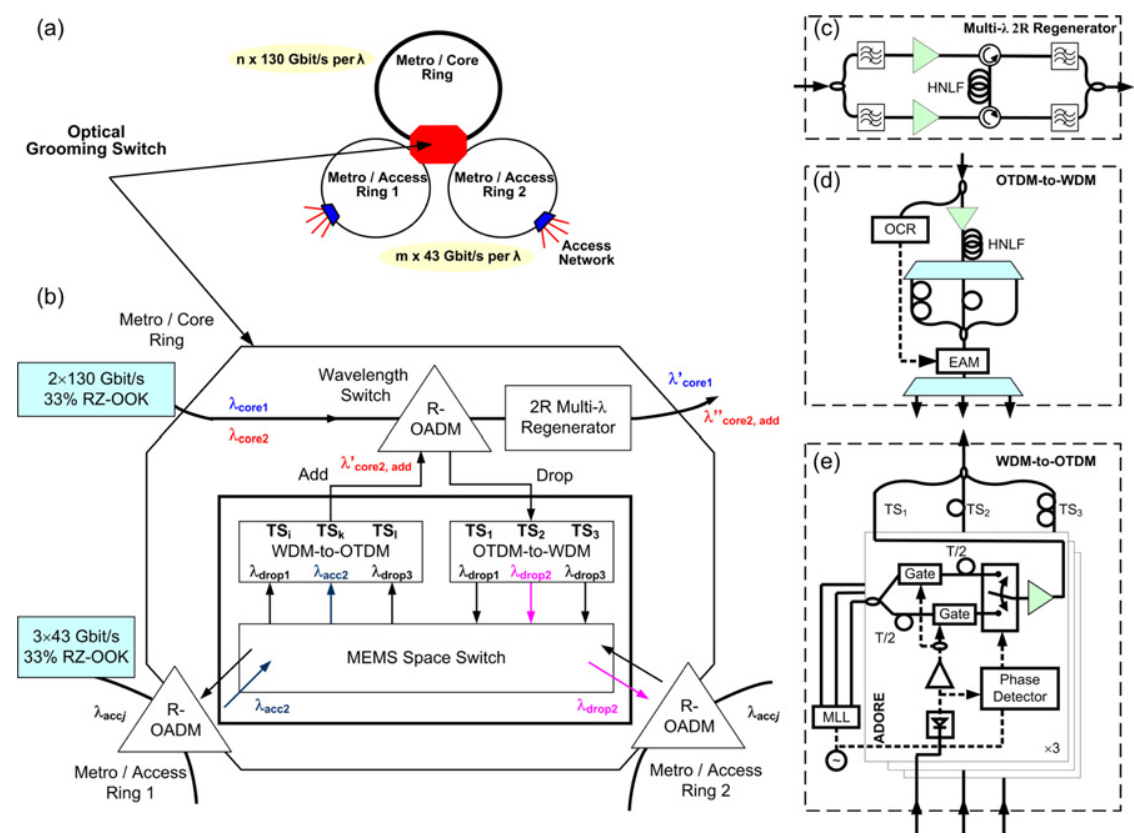

Fig. 1. (Color online) Network scenario and grooming switch node. (a) Two metro/access rings are interconnected to a metro/core ring via the grooming switch. Each ring carries a multiple of WDM channels, either at $43 \mathrm{Gbit} / \mathrm{s}-\mathrm{OOK}$ or $130 \mathrm{Gbit} / \mathrm{s}-\mathrm{OOK}$ per wavelength. (b) Grooming switch block diagram. Key building blocks are the wavelength selective switch (reconfigurable optical add/drop multiplexer (ROADM)), the multi-wavelength $2 R$ regenerator (c), the OTDM-to-WDM converter (d), the MEMS space switch, and the WDM-to-OTDM converter (e).

With optical grooming, transparent interconnection of networks in terms of protocol, format, and bitrate can be offered at much higher capacities than for DXCs.

While current optical nodes enable switching, they cannot provide the necessary transparent mechanism for grooming. This actually means that there is a need for optical grooming switches $[10,11]$ that are also able to aggregate traffic from one network at lower speed traffic to another network with higher speed traffic.

In this paper we demonstrate a novel optical grooming switch. It connects a $130 \mathrm{Gbit} / \mathrm{s}$ core ring fully transparent to $43 \mathrm{Gbit} / \mathrm{s}$ metro/access rings, which are circuit or burst switched. Key functionalities of the node are wavelength division multiplexing to optical time division multiplexing (OTDM) traffic aggregation, OTDM-to-WDM demultiplexing, TSI of TDM tributaries, as well as multi-wavelength $2 R$ regeneration. A microelectromechanical switch (MEMS) in combination with all-optical wavelength conversion guarantees non-blocking space and wavelength switching for any tributary.

\section{THE GROOMING SWITCH AND ITS SUBSYSTEMS}

\section{A. The Switch Working Principle and Functionalities}

The all-optical grooming switch (the red octagon in Fig. 1(a)) is designed to provide connectivity of a $130 \mathrm{Gbit} / \mathrm{s}$ metro/core ring and two $43 \mathrm{Gbit} / \mathrm{s}$ metro/access rings. The traffic of three $43 \mathrm{Gbit} / \mathrm{s}$ WDM channels is groomed to form a $130 \mathrm{Gbit} / \mathrm{s}$ signal in one new WDM channel. In principle, this switch proposal is upgradable to many ports for interconnecting a large number of rings.

Figure 1(b) presents the block diagram of the grooming switch. The metro/core ring carries two WDM channels with $130 \mathrm{Gbit} / \mathrm{s}$ on-off keying (OOK) data signals ( $\lambda_{\text {core } 1}$, $\left.\lambda_{\text {core } 2}\right)$. Each of the $130 \mathrm{Gbit} / \mathrm{s}$ signals consists of three OTDM time slots $\mathrm{TS}_{1}, \mathrm{TS}_{2}$, and $\mathrm{TS}_{3}$. One of the $130 \mathrm{Gbit} / \mathrm{s}$ metro/core ring data signals is passed through the node and the multi-wavelength $2 R$ regenerator to the output $\left(\lambda_{\text {core } 1}^{\prime}\right)$. The other one is first dropped to the OTDM-to-WDM converter, which demultiplexes the OTDM signal with $\mathrm{TS}_{1}, \mathrm{TS}_{2}$, and $\mathrm{TS}_{3}$ into three $43 \mathrm{Gbit} / \mathrm{s} \lambda$-tributaries $\left(\mathrm{TS}_{1} \rightarrow \lambda_{\text {drop } 1}, \mathrm{TS}_{2} \rightarrow\right.$ $\lambda_{d r o p 2}$, and $\left.\mathrm{TS}_{3} \rightarrow \lambda_{d r o p} 3\right)$. A specific switching scenario for example is that the $\lambda$-tributary on wavelength $\lambda_{d r o p 2}$ is then dropped to access ring 2 and replaced by a new $\lambda$-tributary $\left(\lambda_{a c c 2}\right)$ from access ring 1 . $\lambda$-tributaries 1 ( $\left.\lambda_{d r o p 1}\right)$, $3\left(\lambda_{d r o p 3}\right)$, and the new $\lambda$-tributary $\left(\lambda_{a c c 2}\right)$ are then directed to the WDM-to-OTDM converter by means of a MEMS. The WDM-to-OTDM unit comprises three asynchronous digital optical regenerator (ADORE) units. Each unit converts one $\lambda$-tributary to an OTDM time slot (i.e., $\lambda_{d r o p 1} \rightarrow \mathrm{TS}_{1}, \lambda_{\text {acc } 2} \rightarrow$ $\mathrm{TS}_{2}$, and $\lambda_{d r o p 3} \rightarrow \mathrm{TS}_{3}$ ). The OTDM time slots are interleaved to form the OTDM channel on the new wavelength $\lambda_{\text {core } 2, a d d}^{\prime}$. This signal is finally launched to the metro/core ring through the multi-wavelength $2 R$ regenerator.

The switch offers the following key functionalities:

Traffic grooming $[12,13]$ is understood in this paper as the aggregation of low bitrate signals at one wavelength to a high bitrate signal at a different wavelength, and switching of this signal afterwards. 
In this example, the node aggregates $3 \times 43 \mathrm{Gbit} / \mathrm{s} \lambda$ tributaries to a $130 \mathrm{Gbit} / \mathrm{s}$ OTDM signal by utilizing WDM-to-OTDM conversion [14-17]. The OTDM signal is then switched to the metro/core ring through a reconfigurable optical add/drop multiplexer (ROADM).

In addition, an OTDM-to-WDM converter [18] enables demultiplexing of a $130 \mathrm{Gbit} / \mathrm{s}$ high bitrate OTDM signal to three low bitrate $43 \mathrm{Gbit} / \mathrm{s} \lambda$-tributaries.

Time-slot interchanging [12] is the re-allocation of OTDM time slots of metro/core ring OTDM signals per wavelength.

The time slots of the OTDM signal dropped from the metro/core ring can be interchanged from one time slot to any other time slot. This is achieved by utilizing OTDM-to-WDM conversion and reconfiguring the MEMS space switch to provide connections to alternate input ports of the WDM-to-OTDM converter.

Optical multi-wavelength $2 R$ regeneration $[19,20]$ is the simultaneous re-amplification and re-shaping of the various $130 \mathrm{Gbit} / \mathrm{s}$ OTDM signals that leave the node via the metro/core ring. In this example, two OTDM signals are considered.

Wavelength selective optical switching is adding/dropping of an OTDM channel per wavelength and the switching of this channel to a specific path of the node.

It is implemented with a reconfigurable optical add/drop multiplexer and a MEMS space switch.

\section{B. The Reconfigurable Optical Add/Drop Multiplexer}

The ROADM enables wavelength channels to be added (dropped) to (from) the metro/core ring to (from) the metro/access rings respectively. The traffic that is transmitted through the node in the metro/core ring is not affected. In our experiment tunable thin-film filters (TFF) are used.

\section{The Wavelength Selective Switch}

A ROADM in combination with a space switch (MEMS) is a wavelength selective optical switch (WSS). The ROADM in the metro/core ring selects one of the $130 \mathrm{Gbit} / \mathrm{s}$ OTDM signals and drops this channel to the OTDM-to-WDM converter. Following this, the MEMS space switch can redirect each $\lambda$-tributary of this signal either to access ring 1 , access ring 2 , or back to the metro/core ring. Therefore, in our approach a $1 \times 3 \mathrm{WSS}$ is used.

Wavelength tunability of the ROADM and space switching of the data to the desired output port with the MEMS enable reconfigurable bandwidth allocation. This is required to adapt the network for changing traffic demands of the end-users.

\section{The OTDM-to-WDM Converter}

An OTDM channel from the metro/core ring may be dropped via the WSS to the OTDM-to-WDM unit.

The OTDM-to-WDM conversion (Fig. 1(d)) implies a three-stage process. First, the dropped $130 \mathrm{Gbit} / \mathrm{s}$ OTDM signal is replicated onto three different wavelengths by means of a multi-wavelength converter. The wavelength conversion is achieved by spectral broadening of the input signal due to self-phase modulation (SPM) within a highly nonlinear fiber (HNLF) and subsequent filtering at the desired wavelengths (the Mamyshev concept [21]). Second, the three replicas are time aligned using an array of optical delay lines so that the respective time slots coincide. Finally, a time gating using an electro-absorption modulator (EAM) extracts every third pulse inside its corresponding WDM channel. The local clock for the EAM gating is provided by a clock recovery unit (CRU). The output $43 \mathrm{Gbit} / \mathrm{s} \lambda$-tributaries are launched into the MEMS for space switching.

\section{E. The MEMS Space Switch}

Traffic from any of the access rings is switched by means of the MEMS space switch to either metro/access ring or via the add path to the WDM-to-OTDM converter. Each add-port of the MEMS switch relates to a particular time slot of the OTDM signal. TSI includes the possibility of interchanging the time slots of the OTDM signals per wavelength by dropping and looping back one wavelength channel through the add path. Time-slot interchanging functionality is thus obtained by reconfiguration of add-ports within the MEMS. In our experiments an $8 \times 8 \mathrm{MEMS}$ is used.

\section{F. The WDM-to-OTDM Converter}

The WDM-to-OTDM converter (Fig. 1(e)) aggregates the three $43 \mathrm{Gbit} / \mathrm{s} \lambda$-tributaries to a $130 \mathrm{Gbit} / \mathrm{s}$ OTDM signal on one wavelength. It consists of three dual-gate ADORE units, each mapping one $43 \mathrm{Gbit} / \mathrm{s}$ OOK $\lambda$-tributary onto one OTDM time slot. Each ADORE unit provides regeneration, retiming, pulse width adaptation, and wavelength conversion. The OTDM time slots of the $130 \mathrm{Gbit} / \mathrm{s}$ signal are assigned by proper selection of the input $\lambda$-tributaries using the MEMS.

The functional principle of the WDM-to-OTDM converter is as follows. Within each ADORE the data signal on the $\lambda$ tributary is optical-to-electrical converted within a photodiode (PD) and used to drive two Mach-Zehnder modulators (MZMs). The detected signal is also mixed with the local clock to detect the relative phase of the incoming signal. This information is later used to select the correct sampling phase to ensure data integrity between the incoming data on the $\lambda$-tributary and the regenerated and retimed signal at the output of the switch. A mode-locked laser (MLL) generates $2.5 \mathrm{ps}$ (full width at half-maximum) optical pulses with a repetition rate of $43 \mathrm{GHz}$ which are launched into the three ADORE units. For each ADORE these clock pulses are duplicated and delayed by the time of half a bit slot. Then the two trains of clock pulses are launched into the MZMs in order to encode the $43 \mathrm{Gbit} / \mathrm{s}$ data signal onto the MLL pulse trains. In this way, the incoming data signal is sampled at two points during the bit slot. Subsequently, one of the data streams is again delayed by half a bit slot and the two data signals are directed into a $2 \times 1$ optical switch. The modulated pulse stream which is best aligned with the incoming data signal is selected by 




Fig. 2. (Color online) Particular node implementation scenario and corresponding measurement results, where two 130 Gbit/s signals (A \& B) are launched into the node. Signal (A) is regenerated and converted to signal (E); signal (B) is split into its $43 \mathrm{Gbit} / \mathrm{s} \lambda$-tributaries (C) by means of an OTDM-to-WDM converter based on self-phase modulation in a highly nonlinear fiber followed by optical filtering and time gating. $\lambda$-tributary $\lambda_{d r o p 2}$ is dropped to the access ring 2 and a new $\lambda$-tributary $(\mathrm{G})$ is added from access ring 1 . The two $\lambda$-tributaries $\lambda_{d r o p 1}$ and $\lambda_{d r o p 3}$ together with the added $\lambda$-tributary are aggregated by means of different ADORE units and corresponding time-interleaving. The groomed OTDM signal (see $\mathrm{D}$ ) is mapped back to the core ring $(\mathrm{F})$ via the $2 R$ multi-wavelength regenerator. The spectra of the signals (A) to (F) are also shown.

a phase comparator circuit. The output signal will therefore be aligned to a fixed output clock phase independent of the incoming data phase. In this way, the random and time-varying bit-slot phases of the input $\lambda$-tributaries are translated into a fixed phase. Bit slips from synchronization onto the common local clock are accommodated within a guard band between bursts, thus maintaining data integrity. A detailed explanation of the experimental implementation can be found in [22]. The tributaries at the output of each ADORE unit are subsequently bit-slot interleaved to form the $130 \mathrm{Gbit} / \mathrm{s}$ OTDM channel.

\section{G. The Multi-Wavelength $2 R$ Regenerator}

To guarantee the quality of the traffic in the metro/core ring, an all-optical multi-wavelength $2 R$ regenerator (Fig. 1(c)) operating at $130 \mathrm{Gbit} / \mathrm{s}$ is also included. It relies on SPM induced spectral broadening, which takes place in a HNLF, and subsequent filtering at an offset wavelength. This principle is well known for single-channel operation and is extended for two wavelengths in this node. To avoid interchannel distortions by cross-phase modulation (XPM) or four-wave mixing (FWM) a bidirectional propagation of the two data signals is used to achieve a rapid "walk-through" of the data pulses within the adjacent channels [19,20].

\section{NODE IMPLEMENTATION AND RESULTS}

This section will cover the full demonstration of the switch functionalities with multiplexing in wavelength and time.
The excellent performance of the solution will be verified by studying a multitude of switching scenarios, showing dynamic bandwidth allocation for time-varying traffic demands. The experimental implementation and results of the switching scenario are shown in Fig. 2 [23]. The metro/core ring carries two $130 \mathrm{Gbit} / \mathrm{s}$ signals with $\lambda_{\text {core } 1}$ and $\lambda_{\text {core } 2}$ with signal qualities of $Q^{2}=18.7 \mathrm{~dB}$ and $Q^{2}=20 \mathrm{~dB}$, respectively. In a first scenario the $130 \mathrm{Gbit} / \mathrm{s}$ metro/core ring signal (A) is passed through the node and the regenerator to the output (E). The eye diagram shows a signal quality improvement to $21.2 \mathrm{~dB}$. The second $130 \mathrm{Gbit} / \mathrm{s}$ metro/core ring signal (B) is dropped to the OTDM-to-WDM converter by means of the ROADM. The OTDM-to-WDM converter maps the OTDM time slots to three $\lambda$-tributaries (C) at different wavelength. The quality of the three $\lambda$-tributaries is $19.8 \mathrm{~dB}, 19.2 \mathrm{~dB}$, and $18.3 \mathrm{~dB}$, respectively. $\lambda$-tributary 2 with wavelength $\lambda_{d r o p 2}$ is then dropped to access ring 2 and replaced by a new $\lambda$-tributary from access ring 1 with wavelength $\lambda_{a c c 2}(\mathrm{G})$. $\lambda$-tributary 1 ( $\left.\lambda_{d r o p 1}\right), \lambda$-tributary $3\left(\lambda_{d r o p 3}\right)$, and the new $\lambda$-tributary are guided into the WDM-to-OTDM unit which generates a $130 \mathrm{Gbit} / \mathrm{s}$ OTDM metro/core ring signal on wavelength $\lambda_{\text {core } 2, a d d}^{\prime}$ (D). After regeneration, a high quality $130 \mathrm{Gbit} / \mathrm{s}$ signal with a $Q^{2}=22.8 \mathrm{~dB}$ is observed at the output of the switch (F).

Many more switching scenarios are possible. Two other scenarios are considered and the corresponding results are shown in Fig. 3. Scenarios 2 and 3 show the capability of the switch for performing time-slot interchanging. By reordering the $\lambda$-tributary connections to the ADORE units through the 


\begin{tabular}{|c|c|c|c|c|c|}
\hline \multirow{2}{*}{$\begin{array}{l}\text { Switching } \\
\text { Scenario }\end{array}$} & \multicolumn{3}{|c|}{$\lambda^{\prime}$ core2, add Tributaries } & \multicolumn{2}{|c|}{$\lambda$ "corez, add Result at F } \\
\hline & $\mathrm{TS}_{1}$ & $\mathrm{TS}_{2}$ & $\mathrm{TS}_{3}$ & $\mathrm{Q}^{2}[\mathrm{~dB}]$ & Eye Diagram \\
\hline 1 & $\lambda_{\text {drop1 }}$ & $\lambda_{\mathrm{acc} 2}$ & $\lambda_{\text {drop3 }}$ & 22.8 & \\
\hline 2 & $\lambda_{\text {drop2 }}$ & $\lambda_{\mathrm{acc} 2}$ & $\lambda_{\text {acc3 }}$ & 22.9 & \\
\hline 3 & $\lambda_{\text {acc2 }}$ & $\lambda_{\text {drop2 }}$ & $\lambda_{\text {acc3 }}$ & 21.4 & \\
\hline
\end{tabular}

Fig. 3. (Color online) Three switching scenarios with tributaries dropped and looped back onto the core and access network. Scenario 2 and 3 show time-slot interchanging. The signal quality of the eyes of the OTDM multiplexed signals is excellent in all situations.

MEMS switch, TSI is achieved. The switching scenarios 2 and 3 are actually identical except for the interchanging of time slots $\mathrm{TS}_{1}$ and $\mathrm{TS}_{2}$. The quality of the OTDM channels after the $2 R$ multi-wavelength regenerator is $22.9 \mathrm{~dB}$ for scenario 2 and $21.4 \mathrm{~dB}$ for scenario 3 . All $Q^{2}$ factor measurements are performed with random signal polarization using an all-optical sampling scope.

\section{FIELD TRIAL}

The field experiment was aimed at demonstrating the key network functions of the switch dealing with impairments introduced in installed fiber links [24,25]. The field trial (Fig. 4(a)) was performed on the Aurora network, an installed dark fiber network within the UK, dedicated to research purposes. For this experiment, two fully dispersion compensated fiber sections were employed. The first section, Colchester-Ipswich-Colchester, was $100 \%$ pre-compensated using a slope-matched dispersion compensating module and SMF 28. It had a round trip length of $80 \mathrm{~km}$ and represented a metro/access ring with one $43 \mathrm{Gbit} / \mathrm{s}$ channel. The second section, Colchester-Chelmsford-Colchester, represented a ring in the metro/core network and had a round trip length of 110 $\mathrm{km}$. It was $80 \%$ pre-compensated and $20 \%$ post-compensated and carried two $130 \mathrm{Gbit} / \mathrm{s}$ channels.

Several field experiments were implemented. Here we only report on one specific scenario in which the node at Colchester described in Fig. 4(b) was separated in two partial nodes. Partial node 1 (the Ipswich node) connects the metro/access ring through Ipswich to the metro/core ring through Chelmsford. Partial node 2 (the Chelmsford node) drops high bitrate OTDM signals from the metro/core ring to another access ring. More scenarios can be found in [25].

In detail, the Ipswich node performs WDM-to-OTDM aggregation of traffic which originates in a $43 \mathrm{Gbit} / \mathrm{s}$ edge WDM domain. The Chelmsford node performs $2 R$ multi-wavelength regeneration of two $130 \mathrm{Gbit} / \mathrm{s}$ OTDM channels and also OTDM-to-WDM demultiplexing of one of two OTDM channels.

In the experiment one $33 \% \mathrm{RZ}-\mathrm{OOK} 43 \mathrm{Gbit} / \mathrm{s}$ channel is transmitted in access ring 1 through Ipswich to the Ipswich node. Here, another two $43 \mathrm{Gbit} / \mathrm{s}$ local channels are launched to the add path. The data pattern (Fig. 5) consists of a $2^{7}-1$ pseudo-random bit sequence (PRBS) of $1 \mathrm{~ms}$ duration and a single modified $2^{19}-1$ PRBS $1 \mu$ s guard interval with a mark-to-space ratio of $52.5 \%$. This ratio is required to detect the guard interval by observing the change in average power. The data packets and the guard interval were periodically repeated. WDM-to-OTDM aggregation was performed with the assistance of the ADORE unit. The ADORE first detects the guard interval and then performs synchronization of the
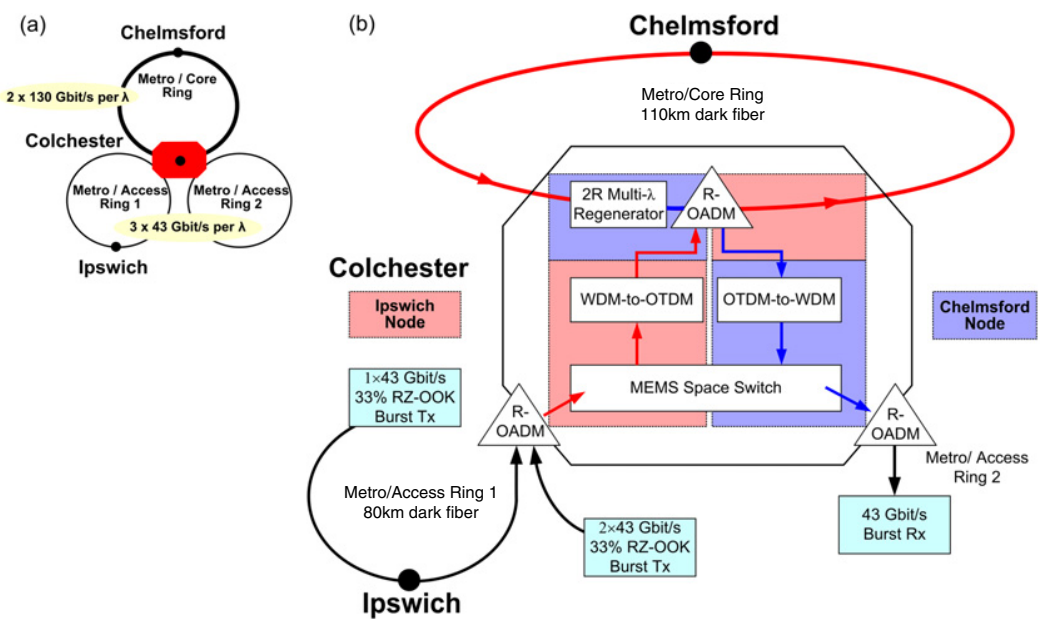

Fig. 4. (Color online) Field trial using an actually installed fiber network. (a) Dispersion compensated dark fiber network between Ipswich, Colchester, and Chelmsford in the UK. (b) Network scenario with $1 \times 43 \mathrm{Gbit} / \mathrm{s}$ burst traffic transmitted across the $80 \mathrm{~km}$ access network to the Ipswich node. Here the traffic is aggregated together with two locally generated $43 \mathrm{Gbit} / \mathrm{s}$ burst signals. Time-slot interchanging can be induced depending on the switching scenario. Then the $130 \mathrm{Gbit} / \mathrm{s}$ burst traffic has been transported on the metro/core ring over a reach of $110 \mathrm{~km}$ to the Chelmsford node where it is $2 R$ multi-wavelength regenerated, demultiplexed, and dropped off into the access network. 


\begin{tabular}{|c|c|c|}
\hline PRBS7 data block & Guard Interval & PRBS7 data block \\
\hline
\end{tabular}

Fig. 5. (Color online) The data frame of the burst switched network consists of a repeating $2^{7}-1$ pseudo-random bit sequence (PRBS) of 1 $\mathrm{ms}$ duration and a single modified $2^{19}-1$ PRBS of $1 \mu \mathrm{s}$ duration serving as a guard interval.

$\lambda$-tributary to the local clock by switching between the two alternate sampling phases. This switching was measured to take place within $440 \mathrm{~ns}$ and entirely inside a guard interval. This assured data block integrity during variations of data phase due to runtime differences in the dark fiber.

Point (A) in Fig. 6 shows the 130 Gbit/s OTDM channel at $1556 \mathrm{~nm}$. It consists of the ADORE output $\lambda$-tributary and two local $\lambda$-tributaries. These local signals are pulse width adapted and wavelength converted onto the same MLL as the ADORE output $\lambda$-tributary. The generated $130 \mathrm{Gbit} / \mathrm{s}$ signal was then combined with another $130 \mathrm{Gbit} / \mathrm{s}$ signal (B) which transited through the node. Both channels are sent over the metro/core ring through Chelmsford. In the Chelmsford node, they were simultaneously $2 R$ regenerated. One OTDM channel transited through the Chelmsford node (C). The second OTDM channel is dropped (D) and OTDM-to-WDM demultiplexed. After space switching the $\lambda$-tributary to the access ring, the signal quality is measured (eye diagrams, bit-error ratios (BER) (E)). Excellent eye diagrams and bit-error ratios were measured at all partial nodes of the field experiment. The BER curves in Fig. 6 show the results of the 130 Gbit/s-to- 43
Gbit/s-EAM-demultiplexed (back-to-back) OTDM channel and the OTDM-WDM converted $\lambda$-tributaries. The power penalty is around $2 \mathrm{~dB}$ and mainly induced by small leading pulses from the MLL source affecting the CRU performance. The values of the signal qualities and eye diagrams have been measured with an all-optical sampling scope unit.

\section{Conclusion}

A novel all-optical switching node with grooming functionality and multi-wavelength regenerative capability has been successfully demonstrated. The node implementation demonstrated the high quality interoperability of the OTDMto-WDM, WDM-to-OTDM, and $2 R$ regeneration subsystems for continuous traffic. Also, in a field trial using dark fiber links, the tolerance to impairments introduced by fiber transmission together with the switching of data between high bitrate $130 \mathrm{Gbit} / \mathrm{s}$ metro/core rings and lower bitrate $43 \mathrm{Gbit} / \mathrm{s}$ metro/access rings has been demonstrated with exceptional performance. The node offers switching functionality in the time, i.e., including time-slot interchanging, space, and wavelength domains. The switch node is expected to boost the progress in the metro networks and to match the technological leaps that have already been carried out at the backbone and the access parts. This approach offers not only broadband access for every user but also interoperability with existing infrastructures providing a smooth migration path from existing to future infrastructures and supporting a variety of new services and applications.

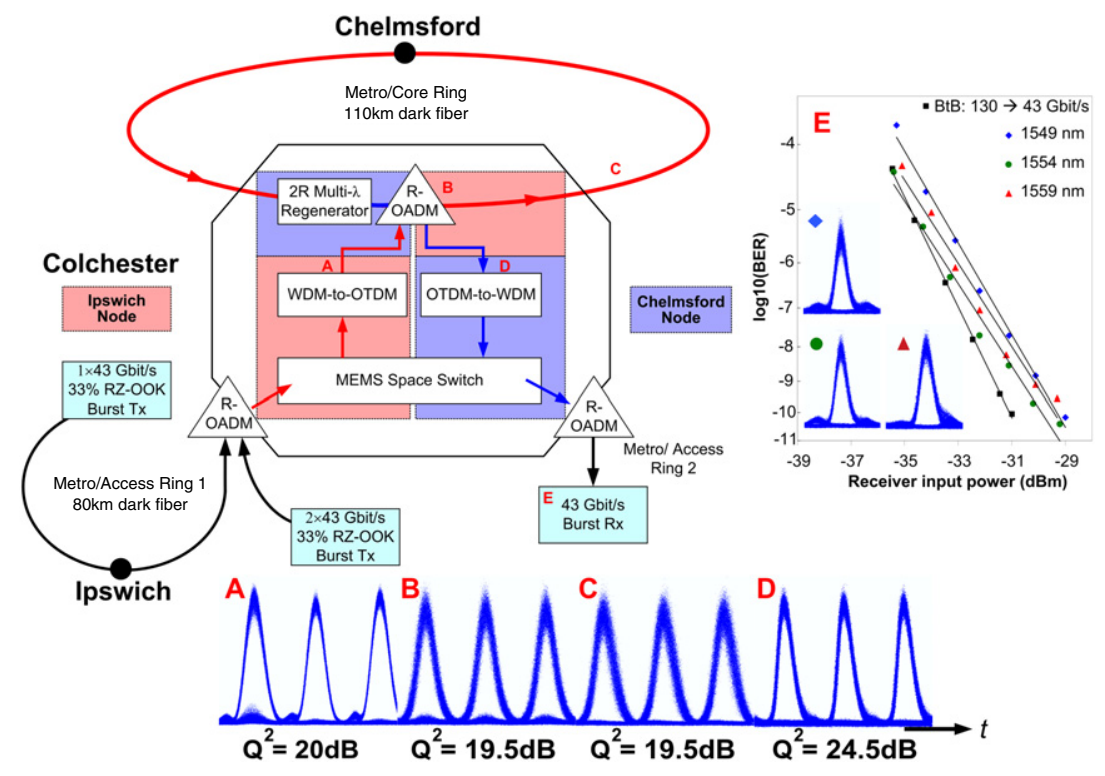

Fig. 6. (Color online) Eye diagrams, signal quality values, and bit-error ratio of the field trial measurements at various points in the dark fiber network. Here, we report the specific scenario in which the Ipswich node performs WDM-to-OTDM conversion of burst traffic which originates in an edge $3 \times 43 \mathrm{Gbit} / \mathrm{s}$ WDM domain. The Chelmsford node performs $2 R$ multi-wavelength regeneration of two $130 \mathrm{Gbit} / \mathrm{s}$ channels and also OTDM-to-WDM demultiplexing of the OTDM channel. Eye diagram (A) shows the groomed OTDM signal consisting of the output of the ADORE unit combined with two MLL pulses converted onto the same wavelength and interleaved. This OTDM signal is combined with a second 130 Gbit/s OTDM signal (B) which transited through the Ipswich node. At the Chelmsford node the two signals are simultaneously regenerated and one channel is dropped (eye (D)), whereas the other channel is passed through the node (C). The OTDM-to-WDM converter generates lower data rate tributaries of $3 \times 43 \mathrm{Gbit} / \mathrm{s}$. After space switching the traffic to the access ring, the signal quality of each tributary is measured (E). 


\section{ACKNOWLEDGMENTS}

This work was supported in part by the European projects TRIUMPH (grant IST-027638 STP) and in part by Euro-Fos (NoE 224402). R. Bonk and D. Hillerkuss acknowledge financial support from the Karlsruhe School of Optics \& Photonics (KSOP) and the German Research Foundation (DFG). A. Ellis acknowledges the financial support from the Science Foundation Ireland under grant number 06/IN/I969.

\section{REFERENCES}

[1] A. M. Saleh and J. M. Simmons, "Evolution towards the next-generation core optical network," J. Lightwave Technol., vol. 24, pp. 3303-3321, 2006.

[2] S. Sygletos, I. Tomkos, and J. Leuthold, "Technology challenges on the road towards transparent networking," J. Opt. Netw., vol. 7, pp. 321-350, 2008.

[3] ITU-T, Gigabit-capable Passive Optical Networks (GPON): Physical Media Dependent (PMD) layer specification, in ITU-T Recommendation G.984.2, 03/2003. http://www.itu.int/rec/T-REC-G/e.

[4] N. Ghani, J.-Y. Pan, and X. Cheng, Metropolitan Optical Networks, Optical Fiber Telecommunications, vol. IVB. Academic Press, 2002, pp. 329-403.

[5] A. Gladisch, R.-P. Braun, D. Breuer, A. Ehrhardt, H.-M. Foisel, M. Jaeger, R. Leppla, M. Scheiders, S. Vorbeck, W. Weiershausen, and F.-J. Westphal, "Evolution of terrestrial optical system and core network architecture," Proc. IEEE, vol. 94, pp. 869-891, 2006.

[6] A. Morea and J. Poirrier, "A critical analysis of the possible cost savings of translucent networks," in Proc. 5th Int. Workshop on Design of Reliable Communication Networks, 2005, pp. 311-317.

[7] P. Humblet, "The direction of optical technology in the metro area," in Optical Fiber Communication Conf., 2001, paper WBB1.

[8] J. Livas, "Optical transmission evolution: from digital to analog to ? network tradeoffs between optical transparency and reduced regeneration cost," J. Lightwave Technol., vol. 23, pp. 219-224, 2005.

[9] O. Leclerc, "Towards transparent optical networks: still some challenges ahead," in Proc. 18th Annual Meeting of the IEEE Lasers and Electro-Optics Society, 2005, pp. 418-419, paper TuCC3 (invited).

[10] R. Nejabati, G. Zervas, G. Zarris, Y. Qin, E. Escalona, M. O'Mahony, and D. Simeonidou, "Multigranular optical router for future networks [invited]," J. Opt. Netw., vol. 7, pp. 914-927, Nov. 2008.

[11] R. S. Barr and R. A. Patterson, "Grooming telecommunications networks," Opt. Netw. Mag., vol. 2, pp. 20-23, 2001.

[12] P. Vorreau, D. Hillerkuss, F. Parmigiani, S. Sygletos, R. Bonk, P. Petropoulos, D. Richardson, G. Zarris, D. Simeonidou, D. Klonidis, I. Tomkos, R. Weerasuriya, S. Ibrahim, A. Ellis, R. Morais, P. Monteiro, S. Ben Ezra, S. Tsadka, W. Freude, and J. Leuthold, " $2 R / 3 R$ optical grooming switch with time-slot interchange," in Eur. Conf. Opt. Commun. 2008 (ECOC'08), 2008, PDP Th.3.F.4.

[13] B. Mukherjee, C. Ou, H. Zhu, N. Singhal, and S. Yao, "Traffic grooming in mesh optical networks," in Optical Fiber Communication Conf., 2004, paper ThG1.

[14] S. Ibrahim, R. Weerasuriya, D. Hillerkuss, G. Zarris, D. Simeonidou, J. Leuthold, D. Cotter, and A. Ellis, "Experimental demonstration of $42.6 \mathrm{Gbit} / \mathrm{s}$ asynchronous digital optical regenerators," in Int. Conf. Transparent Opt. Netw., 2008, paper We.C3.3.

[15] D. Cotter and A. D. Ellis, "Asynchronous digital optical regeneration and networks," J. Lightwave Technol., vol. 16, pp. 2068-2080, Dec. 1998.

[16] D. Hillerkuss, A. Ellis, G. Zarris, D. Simeonidou, J. Leuthold, and D. Cotter, "40 Gbit/s asynchronous digital optical regenerator," Opt. Express, vol. 16, pp. 18889-18894, 2008.

[17] G. Zarris, P. Vorreau, D. Hillerkuss, S. Ibrahim, R. Weerasuriya, A. D. Ellis, J. Leuthold, and D. Simeonidou, "WDM-to-OTDM traffic grooming by means of asynchronous retiming," in Optical Fiber Communication Conf., 2009, paper OThJ6.

[18] R. Morais, R. Meleiro, P. Monteiro, and P. Marques, "OTDMto-WDM conversion based on wavelength conversion and time gating in a single optical gate," in Optical Fiber Communication Conf., 2007, paper OTuD5.

[19] L. Provost, F. Parmigiani, P. Petropoulos, and D. J. Richardson, "Investigation of simultaneous $2 R$ regeneration of two $40 \mathrm{~Gb} / \mathrm{s}$ channels in a single optical fiber," IEEE Photon. Technol. Lett., vol. 20, pp. 270-272, 2008.

[20] F. Parmigiani, P. Vorreau, L. Provost, K. Mukasa, P. Petropoulos, D. J. Richardson, W. Freude, and J. Leuthold, " $2 R$ regeneration of two $130 \mathrm{Gbit} / \mathrm{s}$ channels within a single fiber," in Optical Fiber Communication Conf., 2009, paper JThA56.

[21] P. V. Mamyshev, "All-optical data regeneration based on self-phase modulation effect," in Eur. Conf. Opt. Commun., 1998, pp. $475-476$.

[22] S. Ibrahim, D. Hillerkuss, R. Weerasuriya, G. Zarris, D. Simeonidou, J. Leuthold, and A. D. Ellis, "Novel 42.65 Gbit/s dual gate asynchronous digital optical regenerator using a single MZM," in Eur. Conf. Opt. Commun., 2008, paper Tu4D3.

[23] P. Vorreau, S. Sygletos, F. Parmigiani, D. Hillerkuss, R. Bonk, P. Petropoulos, G. Zarris, D. Simeonidou, D. Klonidis, A. Tzanakaki, I. Tomkos, R. Weerasuriya, S. Ibrahim, A. Ellis, R. Morais, P. Monteiro, S. Ben Ezra, S. Tsadka, W. Freude, and J. Leuthold, "All-optical grooming switch with regenerative functionality for transparent interconnection of networks," Opt. Express, vol. 17, pp. 15173-15185, 2009.

[24] G. Zarris, F. Parmigiani, E. Hugues-Salas, R. Weerasuriya, D. Hillerkuss, N. Amaya Gonzalez, M. Spyropoulou, P. Vorreau, R. Morais, S. Ibrahim, D. Klonidis, P. Petropoulos, A. D. Ellis, P. Monteiro, A. Tzanakaki, D. Richardson, I. Tomkos, R. Bonk, W. Freude, J. Leuthold, and D. Simeonidou, "Field trial of WDM-OTDM transmultiplexing employing photonic switch fabric-based buffer-less bit-interleaved data grooming and all-optical regeneration," in Optical Fiber Communication Conf., 2009, paper PDPC10.

[25] G. Zarris, E. Hugues-Salas, N. Amaya Gonzalez, R. Weerasuriya, F. Parmigiani, D. Hillerkuss, P. Vorreau, M. Spyropoulou, S. Ibrahim, A. D. Ellis, R. Morais, P. Monteiro, P. Petropoulos, D. Richardson, I. Tomkos, J. Leuthold, and D. Simeonidou, "Field experiments with a grooming switch for OTDM meshed networking," J. Lightwave Technol., vol. 28, pp. 316-327, 2010.

R. Bonk (M'06) received a Dipl.-Phys. degree from the Technical University of Braunschweig in 2006. He is currently working toward a $\mathrm{Ph} . \mathrm{D}$. degree in the area of all-optical signal processing using modern devices like quantum dot semiconductor optical amplifiers at the Institute of Photonics and Quantum Electronics, Karlsruhe Institute of Technology (KIT), Karlsruhe, Germany.

P. Vorreau; biography not available at the time of publication. 
D. Hillerkuss; biography not available at the time of publication.

W. Freude (SM'94) received Dipl.-Ing. (M.S.E.E.) and Dr.-Ing. (Ph.D.E.E.) degrees in electrical engineering from the University of Karlsruhe, Karlsruhe, Germany, in 1969 and 1975, respectively. He is a Professor with the Institute of Photonics and Quantum Electronics, Karlsruhe Institute of Technology, Karlsruhe, Germany. His current research activities are in the design and fabrication of high density integrated-optics devices and in photonic crystals. He has published more than 100 papers. He has coauthored a book entitled Optical Communications (Berlin, Germany: Springer-Verlag 1991, in German) and authored and coauthored two book chapters on multimode fibers (Handbook of Optical Communications, Berlin, Springer-Verlag 2002, in German) and microwave modelling of photonic crystals (Photonic Crystals-Advances in Design, Fabrication, and Characterization, Berlin, Wiley-VCH 2004).

Prof. Freude is an Honorary Doctor of the Kharkov National University of Radioelectronics, Kharkov, Ukraine, and a member of VDE/ITG (Verband der Elektrotechnik Elektronik Informationstechnik Informationstechnische Gesellschaft, Germany), OSA, and AAAS. Currently, he is serving as a Vice Chair of the IEEE German LEOS Chapter. Since 2002, he has been a spokesman of the Research Training Group "Mixed fields and nonlinear interactions," which is funded by the Deutsche Forschungsgemeinschaft (DFG), to support young researchers in their pursuit of a doctorate.

G. Zarris received a B.Sc. degree in physics from the University of Patras, Patras, Greece, in 1993, an M.Sc. degree in the physics of laser communications from the University of Essex, Colchester, UK, in 1996, and an MBA degree from Imperial College of Science, Technology and Medicine, London, UK, in 2009. He is currently working toward a Ph.D. degree with the University of Essex. In 1997, he joined Alcatel Submarine Networks, where he led a team in the Product Development Department in the design and development of a number of optical subsystems, including the first undersea optical add-drop multiplexer and the first $980 \mathrm{~nm}$ pumped undersea erbium-doped fiber amplifiers. During a secondment in 1999 in Alcatel, Villarceaux, France, he was involved with the system design of wavelength division multiplexing transmission. In 2000, he joined Ilotron, an optical networking startup. In 2001, he joined Ditech Communications Europe, where he held a senior engineering position and contributed in the system design of an optical cross-connect. Since 2004, he has been a technical member of the Photonic Networks Laboratory, University of Essex. His current research interests include high speed optical transmission and the evolution of optical networking for the transport of high speed Ethernet. He has authored and coauthored various publications and six patent applications relating to optical communications.

D. Simeonidou is the Head of the High Performance Networks Group at the University of Essex, UK. In 1987 and 1989 she received a B.Sc. and an M.Sc. from the Physics Department of the Aristotle University of Thessaloniki in Greece and in 1994 a Ph.D. degree from the University of Essex. She joined Essex as an academic in 1998 after four years with Alcatel Submarine Networks. While in Alcatel, she held the post of Senior Principal Engineer, and contributed to the introduction of WDM in long-haul submarine links and pioneered the design and deployment of optical add-drop multiplexers. At Essex, she is leading a group of 30 academics and researchers and currently involved in 12 national and EU funded projects. Her research focuses on the fields of optical networks, Grid and cloud computing, and future Internet. She is a leading member of the international optical networking and Grid computing research communities and chairs standardization groups and forums in the relevant bodies. She is the author and coauthor of over 350 papers, 11 patents and several standardization documents.

F. Parmigiani was born in Milan, Italy. She graduated with honors in electronic engineering at Politecnico di Milano, Milano, Italy, in 2002, and received a Ph.D. degree in optical communication systems at the Optoelectronics Research Centre (ORC), University of Southampton, Southampton, UK, in 2006. She is currently a Senior Research Fellow at the ORC. In April 2010 she was awarded a prestigious Postdoctoral Research Fellowship from the Royal Academy of Engineering, in support of her research on the combination of all-optical signal processing and advanced modulation formats. Her research interests include ultra-fast all-optical sampling techniques, pulse shaping using specialized fiber Bragg gratings, all-optical nonlinear processing and switches, mainly in optical fibers, as well as advanced modulation formats. Dr Parmigiani is a member of the Optical Society of America (OSA).

P. Petropoulos was born in Patras, Greece. He graduated from the Department of Electrical Engineering and Information Technology, University of Patras, in 1995, received an M.Sc. degree in communications engineering from the University of Manchester Institute of Science and Technology, Manchester, UK, in 1996, and a $\mathrm{Ph} . \mathrm{D}$. degree in optical telecommunications from the Optoelectronics Research Centre (ORC), University of Southampton, Southampton, UK, in 2000 . He is currently a Reader at the ORC. His research interests include all-optical processing and switching in optical fibers; pulse manipulation for optical communications using fiber Bragg gratings, including applications in optical correlation systems for the implementation of optical code division multiple access and optical packet switched systems; silica and compound glass holey fibers and their nonlinear applications; and fiber lasers. His research has produced more than 240 papers in journals and conferences in the field of optical physics and optical communications. Dr. Petropoulos is a member of the Optical Society of America.

R. Weerasuriya was born in Galle, Sri Lanka, in 1976. He received a B.Sc. Eng. degree from the University of Moratuwa, Sri Lanka, in 2002, and an M.Sc. degree from the University of Nottingham, UK, in 2007. He is currently working toward a Ph.D. degree with Tyndall National Institute, University College Cork, Cork, Ireland.

From 2002 to 2006, he was with the Dialog Telekom Ltd., Colombo, Sri Lanka, where he was engaged in terrestrial, satellite transmission and network monitoring systems. In 2006, he moved to the UK for higher education purposes. He is a member of the Photonics System Group, Tyndall National Institute. His research interests include the study of long-haul optical transmission systems, fiber nonlinearities and their applications, and optical regeneration methods in high speed optical networks.

S. Ibrahim (M'05) received his B.Sc. and M.Sc. degrees in electronics and communication engineering from the University of Baghdad, Baghdad, Iraq, in 1999 and 2002, respectively, and a Ph.D. degree (Dr.-Ing.) in electrical engineering from the University of Paderborn, Paderborn, Germany, in 2007. His Ph.D. thesis was entitled "Study of multilevel modulation formats for high-speed digital optical communication systems."

He joined the Chair for Optical Communications and HighFrequency Engineering in the Department of Electrical Engineering, University of Paderborn, Germany, as a Graduate Student/Research Associate at the end of 2002, and obtained a scholarship from the Graduate School of Dynamic Intelligent Systems at the University of Paderborn for the period 2003-2006. In December 2007 he joined the Photonic Systems Group as a Postdoctoral Researcher. His current research interest is in the area of optical communications involving coherent WDM, advanced modulation formats, and optical networks.

Dr.-Ing. Ibrahim is also a member of the IEEE Photonics Society.

A. D. Ellis was born in Underwood, UK, in 1965. He received a B.Sc. degree in physics with a minor in mathematics from the University of Sussex, Brighton, UK, in 1987, and a Ph.D. degree in electronic and electrical engineering from the University of Aston in Birmingham, Birmingham, UK, in 1997.

He was with the British Telecom Research Laboratories as a Senior Research Engineer, where he investigated the use of optical amplifiers and advanced modulation formats in optical networks. He was also at Corning Research Centre as a Senior Research Fellow, where he led activities in optical component characterization. Currently, he is 
the Head of the Transmission and Sensors Group, Tyndall National Institute, University of Cork, Cork, Ireland, where he is also a member of the Department of Physics. His research interests include the evolution of core and metro networks, and the application of photonics to sensing.

He is the author or coauthor of more than 100 journal papers and 20 patents published in the field of photonics.

Dr. Ellis is a member of the Institute of Physics and the Institute of Engineering Technology. He is a Chartered Physicist. He was a reviewer for the IEEE Journal of Lightwave Technology and Photonics Technology Letters.

\section{Klonidis; biography not available at the time of publication}

Dr. I. Tomkos (B.Sc., M.Sc., Ph.D.) has been with the Athens Information Technology Center (AIT) since Sept. 2002. In the past, he was a Senior Scientist (1999-2002) at Corning Inc., USA, and a Research Fellow (1995-1999) at the University of Athens, Greece. At AIT he founded and serves as the Head of the "High Speed Networks and Optical Communication (NOC)" Research Group that was and is involved in many EU funded research projects (including eight running FP7 projects) within which Dr. Tomkos is representing AIT as Principal Investigator and has a consortium-wide leading role (e.g., Project Leader of the EU ICT STREP project DICONET, Project Leader of the EU ICT STREP project ACCORDANCE, Technical Manager of the EU ICT STREP project SOFI, Technical Manager of the EU IST STREP project TRIUMPH, Chairman of the EU COST 291 project, WP leader in many other projects). He is also the Chairman of the Working Group on "Core Network Design and Transmission" within the GreenTouch Initiative/Consortium, anindustry-driven initiative focusing on improving the energy efficiency of telecom networks, and a member of the industry-driven Fiber to the Home Council Europe, which aims to promote the deployment of FTTH in Europe.

Dr. Tomkos received in 2006 the prestigious title of "Distinguished Lecturer" of IEEE Communications Society for the topic of transparent optical networking. Together with his colleagues and students he has authored over 330 peer-reviewed archival articles (an updated list may be found using the "Publish or Perish" tool; over 175 IEEE sponsored items may be found through IEEE Xplore), including about 100 journal/magazine/book publications and 230 conference/workshop proceedings papers. Dr. Tomkos has served as the Chair of the International Optical Networking Technical Committee of the IEEE Communications Society (2007-2008) and the Chairman of the IFIP working group on "Photonic Networking" (2008-2009). He is currently the Chairman of the OSA Technical Group on Optical Communications (2009-2010) and the Chairman of the IEEE Photonics Society Greek Chapter (2010). He has been General Chair, Technical Program Chair, Subcommittee Chair, Symposium Chair, or/and member of the steering/organizing committees for the major conferences (e.g., OFC, ECOC, IEEE GlobeCom, IEEE ICC, ONDM, BroadNets, etc.) in the area of telecommunications/networking (more than 100 conferences/workshops). In addition he is a member of the Editorial Boards of the IEEE/OSA Journal of Lightwave Technology, the IEEE/OSA Journal of Optical Communications and Networking, the IET Journal on Optoelectronics, and the International Journal on Telecommunications Management. He is a Fellow of the IET.

J. Leuthold (S'95-A'98-M'99-SM'03) received a master's degree in physics (Dipl. Phys. ETH) from the Swiss Federal Institute of Technology (ETH), Zürich, Switzerland, in 1991. He received a Ph.D. degree from the Micro- and Optoelectronics Institute, Swiss Federal Institute of Technology.

From 1992 to 1998, he was with the Micro- and Optoelectronics Institute, Swiss Federal Institute of Technology. During this time, he was involved in the modeling, design, and characterization of the integrated all-optical devices for high speed telecommunication applications. After a short postdoctoral period with Tokyo University, Tokyo, Japan, in spring 1999, he moved to Bell Labs, Lucent Technologies, Holmdel, NJ, where he was affiliated, until June 2004. With Bell Labs, he worked on III-V semiconductors for high speed telecommunication applications and performed system experiments with high speed components. Since July 2004, he has been a Professor with Karlsruhe Institute of Technology, Karlsruhe, Germany, where he is the Head of the Institute Photonics and Quantum Electronics. 